\title{
Frutos de cultivares de morangueiros submetidos ao 1-mcp em temperatura refrigerada
}

Fruits of strawberry cultivars submitted to 1-MCP in refrigerated and ambient temperatures

\author{
E. S. Dantas ${ }^{1 *} ;$ T. N. H. Rebouças ${ }^{1}$; J. M. Q. Luz²; C. L. F. Amaral ${ }^{1}$ \\ 'Programa de Pós-graduação em Agronomia, área de Concentração em Fitotecnia, Departamento de Fitotecnia e \\ Zootecnia, Universidade Estadual do Sudoeste da Bahia, 45031-900, Vitória da Conquista, Bahia, Brasil \\ ${ }^{2}$ Instituto de Ciências Agrárias, Universidade Federal de Uberlândia, 38048-100, Uberlândia, Minas Gerais, \\ Brasil
}

*ednaldoagro21@hotmail.com

(Recebido em 18 de junho de 2017; aceito em 25 de setembro de 2017)

\begin{abstract}
O morango é um fruto com rápida perecibilidade, mesmo assim, há poucos trabalhos na literatura a respeito do uso de produtos para aumentar a sua conservação pós-colheita. Assim, o estudo teve o objetivo de avaliar a qualidade e a conservação de frutos de duas cultivares de morango, submetido ao 1-Metilciclopropeno (1$\mathrm{MCP}$ ), armazenados sob temperatura refrigerada. Foram avaliadas as cultivares Albion e San Andreas. Os frutos foram colocados em câmaras fechadas e submetidos ao tratamento com $100 \mathrm{~nL} \mathrm{~L}^{-1}$ de 1-MCP pelo período de duas horas. Após o período de aplicação, os frutos foram embalados e armazenados sob temperatura de $4^{\circ} \mathrm{C} \pm 1^{\circ} \mathrm{C}$ e umidade relativa de $90 \% \pm 5 \%$ por 24 dias. O delineamento experimental foi inteiramente casualizado com três repetições e oito frutos por parcela, sendo adotado o esquema fatorial 13 x 2 × 2 (13 tempos de avaliação - dias $0 ; 2 ; 4 ; 6 ; 8 ; 10 ; 12 ; 14 ; 16 ; 18 ; 20 ; 22$ e 24; duas cultivares, Albion e San Andreas; e dois tratamentos, tratados com 1-MCP e controle. Os frutos foram avaliados quanto à firmeza, perda de massa, pH, sólidos solúveis, acidez titulável, ácido ascórbico, antocianinas totais e carotenoides totais. O uso do 1-MCP não foi eficiente em alterar as características de qualidade avaliadas, pois estas evoluíram normalmente, em ambas as cultivares.
\end{abstract}

Palavras-chave: Pós-colheita, San Andreas, Albion

The strawberry is a fruit with rapid perishability, however, there are few studies in the literature regarding the use of products to increase their post-harvest conservation. Due to lack of information, the objective of this study was to evaluate the quality and conservation of fruits of two strawberry cultivars, submitted to 1Methylcyclopropene (1-MCP), stored under refrigerated temperature. Strawberries of the Albion and San Andreas cultivars were evaluated. The fruits were placed in closed chambers and treated with $100 \mathrm{~nL} \mathrm{L-1}$ of 1-MCP for a period of two hours. After the application period, the fruits were packed and stored under a temperature of $4{ }^{\circ} \mathrm{C} \pm 1{ }^{\circ} \mathrm{C}$ and a relative humidity of $90 \% \pm 5 \%$ for 24 days. The experimental design was completely randomized with three replicates and eight fruits per plot, with the factorial scheme $13 \times 2 \times 2$ (13 evaluation times - days $0 ; 2 ; 4 ; 6 ; 8 ; 10 ; 12 ; 14 ; 16 ; 18,20,22$ and 24, two cultivars, Albion and San Andreas, and two treatments, treated with 1-MCP and control. The fruits were evaluated for firmness, weight loss, $\mathrm{pH}$, soluble solids, titratable acidity, ascorbic acid, total anthocyanins and total carotenoids. The use of $1-\mathrm{MCP}$ was not efficient in altering the quality characteristics evaluated, since these evolved normally in both cultivars.

Keywords: Post-harvest, San Andreas, Albion

\section{INTRODUÇÃO}

A produção mundial de morango é liderada pela China, responsável por 3.005 .304 toneladas, seguida dos Estados Unidos e México, com 1.360 .869 e 379.464 toneladas, respectivamente [1]. O Brasil não é um grande produtor mundial, entretanto detém a segunda maior produção da América Latina com produção anual estimada em 133 mil toneladas atrás apenas do Chile $[2,3]$ e área cultivada de, aproximadamente, 4.000 hectares.

No Brasil o morangueiro é cultivado em locais de clima ameno das regiões Sul, Sudeste, CentroOeste e Nordeste do Brasil, apresentando grande importância social e econômica devido ao número 
de empregos gerados durante o ano em toda a cadeia produtiva e por ser cultivado predominantemente por pequenos e médios produtores, permitindo a diversificação agrícola [4]. No estado da Bahia, o cultivo é recente e encontra-se em fase de expansão na região da Chapada Diamantina onde as condições edafoclimáticas tem propiciado o desenvolvimento dessa cultura.

O morango é uma hortaliça com rápida degradação e perda de qualidade pós-colheita, o que limita o tempo de comercialização e gera perdas elevadas, que podem chegar a $100 \%$ em até três dias em temperatura ambiente. De acordo com Caner et al. (2008) [5] somente com armazenamento e métodos de conservação adequados é possível reduzir as perdas e estender sua vida útil. Além da refrigeração, técnica mais difundida, há outros métodos que podem ser aplicados isoladamente ou em associação, como o uso de reguladores do etileno.

Um regulador de etileno largamente utilizado é o 1-Metilciclopropeno (1-MCP), composto volátil que inibe a ação do etileno sobre o amadurecimento, aumenta a vida pós-colheita e a mantém a qualidade por maior tempo [6].

O 1-MCP tem se mostrado um antagonista efetivo da ação do etileno em sapoti [7], banana [8]; maçã $[9,10]$; abacate [11], entre outras espécies. Embora haja poucos estudos de 1-MCP em morangos, já foi constatado que este regulador aumenta a conservação pós-colheita desses frutos $[12,13,14]$.

Dessa maneira, o estudo teve como objetivo avaliar a qualidade e a conservação de frutos de duas cultivares de morangueiro, submetido ao 1-Metilciclopropeno (1-MCP) e armazenados sob temperatura refrigerada.

\section{MATERIAL E MÉTODOS}

O experimento foi realizado no Laboratório Biofábrica da Universidade Estadual do Sudoeste da Bahia, campus de Vitória da Conquista, Bahia, no mês de julho de 2016. Foram utilizados frutos de morangueiro (Fragaria x ananassa Duch.) das cultivares Albion e San Andreas produzidas em pomar comercial situado a 1.066 metros de altitude, coordenadas $13^{\circ} 26^{\prime}$ '06" de Latitude Sul e $41^{\circ}$ 17 '26" de Longitude Oeste no município de Ibicoara, Bahia.

Os frutos foram colhidos no estádio de maturação comercial (80\% vermelho) nas primeiras horas do dia. Em seguida, foram acondicionados e transportados ao Laboratório da Biofábrica da Universidade Estadual do Sudoeste da Bahia - UESB, onde foram lavados com água potável, sanitizados com imersão por 15 minutos em solução de hipoclorito de sódio a 0,05\% e dispostos para secagem natural em bancada revestida com papel Kraft. Após a secagem, foi realizada a seleção de 1.248 frutos de acordo com a uniformidade de cor, tamanho e ausência de injúrias mecânicas e fisiológicas. Foi utilizado o delineamento inteiramente casualizado (DIC), sendo os tratamentos arranjados em esquema fatorial 13 × 2 × 2: 13 tempos de avaliação (correspondentes aos dias $0 ; 2 ; 4 ; 6 ; 8 ; 10 ; 12 ; 14 ; 16 ; 18 ; 20 ; 22 ; 24)$; duas cultivares (Albion e San Andreas) e duas doses de 1-MCP (controle e $100 \mathrm{~nL} \mathrm{~L}^{-1}$ de $1-\mathrm{MCP}$ ). A parcela experimental foi composta por oito frutos e três repetições, totalizando 156 parcelas e 1.248 frutos, 624 frutos de cada cultivar.

Para a aplicação do 1-MCP foram construídas câmaras herméticas, utilizando caixas de poliestireno de 100 litros revestidas internamente com lona. Na lateral dessa caixa, foi colocado um par de luvas de borracha, devidamente preso, para facilitar o manuseio do gás 1-MCP. Esse par de luvas possibilitou a liberação do gás 1-MCP dentro da câmara com a tampa já fechada, evitando trocas do ar do interior com o exterior da câmara. Para a obtenção do 1-MCP na forma de gás, o produto comercial - que se apresenta na forma de pó - foi colocado em recipiente hermético de vidro de $60 \mathrm{~mL}$ e dissolvido em $25 \mathrm{~mL}$ de água deionizada à temperatura de $40^{\circ} \mathrm{C}$.

A solução foi, posteriormente, agitada até total dissolução. Esse recipiente foi colocado dentro da câmara hermética juntamente com os morangos, em seguida a câmara foi fechada. Com o auxílio do par de luvas fixado na lateral da câmara abriu-se o recipiente contendo 1-MCP já com a câmara vedada. Os frutos foram mantidos por duas horas em contato com o 1-MCP. Os morangos do tratamento controle foram mantidos nas mesmas condições, porém sem tratamento com 1-MCP. Para a obtenção da concentração de $100 \mathrm{~nL} \mathrm{L-}^{-1}$ foi pesado 0,0144 gramas por câmara de aplicação. Ao final desse período, os frutos foram retirados das câmaras e acondicionados em embalagens de polietileno com dimensões de $17,5 \mathrm{~cm}$ de comprimento, $11,5 \mathrm{~cm}$ de largura e $3,8 \mathrm{~cm}$ de 
profundidade, previamente codificadas com o nome do tratamento e cultivar e armazenados em câmara refrigerada à temperatura de $4^{\circ} \mathrm{C} \pm 1^{\circ} \mathrm{C}$ e umidade relativa de $90 \% \pm 5 \%$ por 20 dias. Todas as análises iniciaram no dia zero e prosseguiram até o vigésimo dia. Avaliou-se:

- Perda de massa: obtida com auxílio de uma balança de precisão digital, com resultados expressos em porcentagem, considerando-se a diferença entre a massa inicial (dia zero) e a massa obtida a cada dois dias de análise. Para essa análise uma mesma parcela foi pesada durante todo o período experimental; Firmeza: mensurada em um penetrômetro digital de bancada, onde os frutos inteiros foram submetidos a uma força até ocorrer o rompimento da epiderme. Foram realizadas duas leituras em lados opostos na região equatorial dos frutos, com resultados expressos em Newtons $(\mathrm{N})$. Depois de realizada a verificação de firmeza, retirou-se o cálice dos frutos e estes foram triturados em liquidificador para a obtenção da polpa e posteriores avaliações físicoquímicas.

- $\mathrm{pH}$ : foi determinado por potenciometria digital em eletrodo de vidro, utilizando-se um peagâmetro previamente calibrado em soluções tampão $\mathrm{pH}$ 4,0 e 7,0. As leituras foram realizadas diretamente na polpa de morango [15]. Os sólidos solúveis foram determinados com um refratômetro digital com ajuste automático de temperatura de acordo metodologia da AOAC (2005) [15].

- Acidez titulável: foi verificada por meio de uma amostra de 10 gramas de polpa com os resultados expressos em \% de ácido cítrico, seguindo a metodologia do (Instituto Adolf Lutz - IAL, 2008) [16].

- Relação sólidos solúveis e acidez titulável (SS/ATT): foi obtida pela razão entre os teores de sólidos solúveis e de acidez titulável.

- Teor de ácido ascórbico: foi obtido por meio de uma amostra de 10 gramas de polpa com os resultados expressos em $\mathrm{mg}$ de ácido ascórbico por $100 \mathrm{~g}$ de polpa [15]. A determinação dos carotenoides totais e das antocianinas totais foi realizada na matéria fresca com adaptação do método validado por Sims e Gamon (2002) [17].

Os dados foram submetidos à análise de variância e as médias de cultivares e de tratamento, quando significativas, foram comparadas pelo teste Tukey a 5\% de probabilidade. Para a descrição das variáveis em função dos períodos de armazenamento, utilizaram-se análises de regressão e o modelo polinomial foi selecionado observando-se a significância do teste $\mathrm{F}$ para cada modelo e seus respectivos coeficientes de determinação. As análises estatísticas foram realizadas com o auxílio do Software SISVAR versão 5.6 [18].

\section{RESULTADOS E DISCUSSÃO}

A firmeza é um parâmetro importante da pós-colheita, pois afeta a qualidade, tempo de armazenamento e até mesmo a comercialização imediata dos produtos. Houve diferença significativa na comparação entre os frutos controle das cultivares avaliadas, com valores médios de firmeza de 10,6 N e 13,0 N para Albion e San Andreas, respectivamente. Este resultado corrobora com o relatado por Antunes et al. (2014) [19] que estudando a qualidade pós-colheita de seis diferentes cultivares de morango, observaram maior firmeza para a cultivar San Andreas em relação à cultivar Albion.

Na comparação dos frutos com 1-MCP não houve nenhuma diferença estatística entre as cultivares (12,67 N para Albion e 13,24 N para San Andreas). Isso ocorreu porque o tratamento com 1-MCP manteve a firmeza média dos frutos da cultivar Albion em mais de 2,0 N quando comparado com os frutos controle e, ao mesmo tempo, por esse inibidor de etileno não ter promovido nenhuma diferença significativa na firmeza dos frutos com e sem 1-MCP da cultivar San Andreas. Resultado semelhante ao observado para a cultivar Albion foi encontrado por Silva (2010) [12] ao estudar o efeito do 1-MCP na conservação de morango (cv. Oso-Grande) onde a maior média de firmeza também foi observada nos frutos com 1-MCP em relação aos frutos controle

Ao longo do armazenamento houve decréscimo da firmeza para ambas as cultivares, sem interação entre os dias de armazenagem e 1-MCP ou entre dias e cultivares. Houve diferença estatística apenas para os dias armazenamento. No início do armazenamento a cultivar Albion 
apresentou firmeza de 12,0 N, enquanto a firmeza da cultivar San Andreas foi de 14,33 N demonstrando que a cultivar San Andreas é mais firme que a Albion, como relatado por Antunes et al. (2014) [19]. Porém o comportamento de ambas as cultivares durante o armazenamento não distinguiu e a perda média de firmeza foi $30 \%$ (Figura 1).

O 1-MCP não retardou a perda de firmeza do morango devido, possivelmente, à fisiologia póscolheita, visto que se trata de um fruto não climatérico, porém com intenso metabolismo, o que pode fazer com que as pectinas, responsáveis por sua resistência, sejam degradadas rapidamente, deixando os frutos vulneráveis ao rompimento.

A perda da firmeza nos frutos durante o armazenamento pode estar relacionada com a solubilização das pectinas, uma vez que o processo de solubilização das substâncias pécticas contribui para o amaciamento dos tecidos das frutas em decorrência da redução da força de coesão entre as células [6].
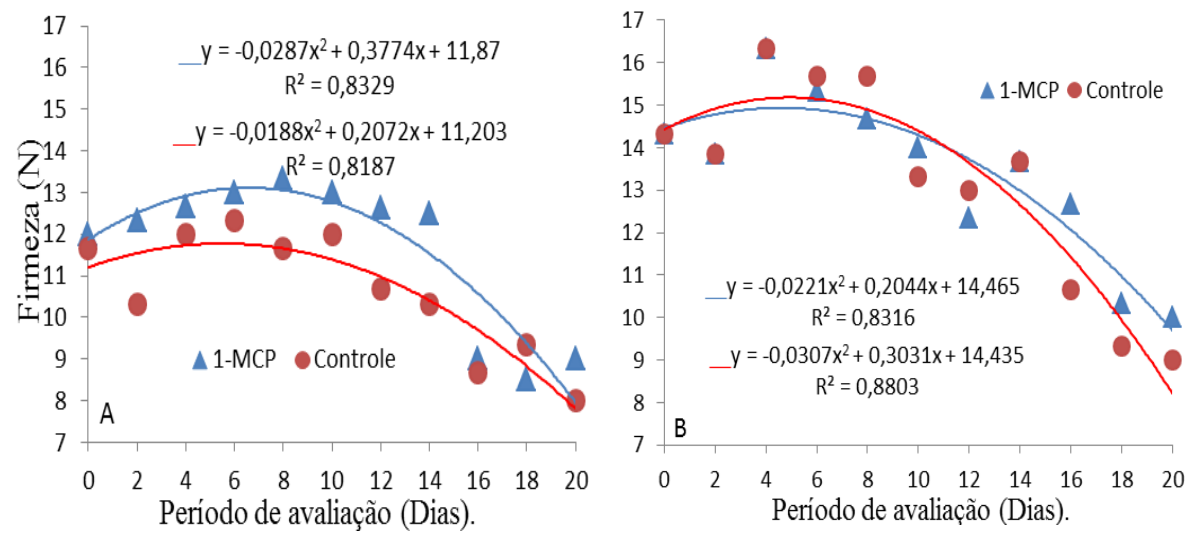

Figura 1.Firmeza ( $N)$ de frutos de morangueiro das cultivares Albion (A) e San Andreas (B) com e sem tratamento de 1-MCP e armazenados sob temperatura de $4 \pm 1^{\circ} \mathrm{C}$ e UR de $90 \% \pm 5 \%$ por 20 dias. Vitória da Conquista - BA, 2016.

Ocorreu perda linear de massa nos frutos de ambos os tratamentos, durante o período de armazenamento, independente da cultivar (Figura 2). A análise de variância mostrou diferença significativa para os dias de armazenamento. A perda média de massa foi de $2,2 \%$ durante o período, valor abaixo de $10 \%$ considerado como suficiente para depreciar os frutos [6]. Inferior também do limite de $6 \%$ considerado como limite para frutos de morango [20].

Este resultado diverge do encontrado por Silva (2010) [12] que, estudando morangos da cultivar Oso-Grande, relatou maior perda de massa durante o armazenamento para os frutos controle em relação àqueles tratados com 1-MCP. Segundo a autora, a diferença entre os tratamentos chegou a $65 \%$, ou seja, os frutos controle perderam $65 \%$ mais massa que os com 1-MCP.

De acordo com Kader (2002) [21] a diminuição da massa está relacionada principalmente com a perda de água para a atmosfera pela transpiração. Dessa maneira, pode-se inferir que as condições deste experimento, onde os frutos ficaram em câmara com $90 \% \pm 5 \%$ de umidade relativa, pode justificar a baixa perda de massa, pois o teor de água da atmosfera interna da câmara já se encontrava bastante elevado. 

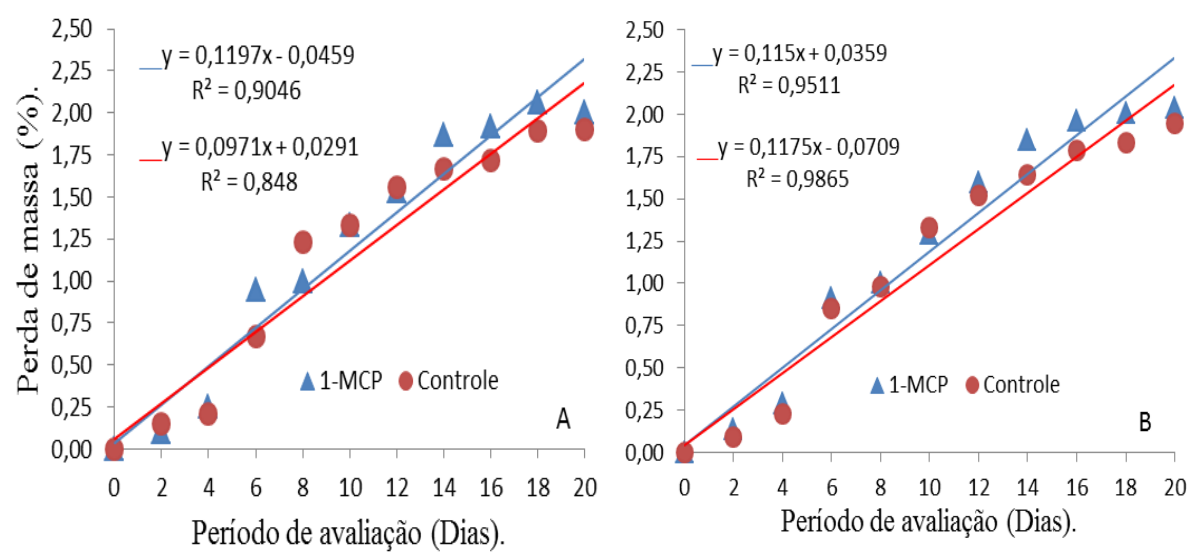

Figura 2. Perda de massa (\%) de frutos de morangueiro das cultivares Albion (A) e San Andreas (B) com e sem tratamento de 1-MCP e armazenados sob temperatura de $4 \pm 1^{\circ} \mathrm{C}$ e UR de $90 \% \pm 5 \%$ por 20 dias. Vitória da Conquista - BA, 2016.

Carvalho (2013) [2] estudando a qualidade e conservação pós-colheita de diferentes cultivares de morango armazenado à temperatura de $1 \pm 0,5^{\circ} \mathrm{C}$ e UR $90 \pm 5 \%$ observaram perda de massa de $1,28 \%$ e 1,19\% para as cultivares Albion e San Andreas, respectivamente, aos 8 dias pós-colheita. Resultado semelhante ao encontrado nesse trabalho, se observado a proporcionalidade do período armazenamento.

$\mathrm{O} \mathrm{pH}$ apresentou o mesmo comportamento durante o armazenamento para os frutos tratados com 1-MCP e sem 1-MCP, com diferença significativa apenas para dias e para cultivares. Esse resultado difere do observado por Silva (2010) [12], que estudando frutos de morangueiro (cv. OsoGrande) tratados com 1-MCP relatou que no tratamento controle o $\mathrm{pH}$ foi maior. Dessa maneira, pode-se inferir que o 1-MCP age distintamente não apenas de acordo à espécie, mas também em cultivares de uma mesma espécie, e que qualquer mínima diferença genética pode ser o limiar que define a ação do 1-MCP em frutos de morangueiro.

Os frutos da cultivar Albion apresentaram um $\mathrm{pH}$ ligeiramente mais elevado que a cultivar San Andreas, com média de 3,20 e 3,10, respectivamente. $\mathrm{O}$ pH de ambas as cultivares ficaram abaixo do requerido para o consumo in natura, que é de no mínimo 3,5.

Até os 12 dias houve aumento do $\mathrm{pH}$ com posterior decréscimo para ambas as cultivares, porém para a cultivar Albion, aos vinte dias, não foi observada nenhuma diferença de $\mathrm{pH}$ em relação ao dia zero. Já a cultivar San Andreas, embora tenha apresentado o mesmo comportamento que a Albion, ao final do armazenamento, o pH estava mais baixo que no dia zero (Figura 3).

Este pode ser um comportamento das cultivares, visto que Carvalho (2013) [2] avaliando a produção, qualidade e conservação pós-colheita de diferentes cultivares de morango, armazenado à temperatura de $1 \pm 0,5^{\circ} \mathrm{C}$ e UR $90 \pm 5 \%$, observou que o $\mathrm{pH}$ da cultivar Albion variou de 3,37 no dia da colheita, atingindo o pico de 3,68 aos 4 dias e decrescendo para 3,24, aos seis dias de armazenamento. A mesma autora também avaliou a cultivar San Andreas e observou pH de 3,19 no dia da colheita, com pico de 3,49 aos 4 dias e decréscimo para 3,0 aos seis dias de armazenamento, valores próximos ao deste trabalho.

Salienta-se que o $\mathrm{pH}$ de frutas e hortaliças, inclusive do morango, pode variar em função de distintas caraterísticas do cultivo e colheita, não sendo apenas resultado do fator genético da cultivar, visto que uma mesma cultivar poderá apresentar valores distintos de $\mathrm{pH}$ de acordo com o local, época e manejo do cultivo, colheita e armazenamento. 

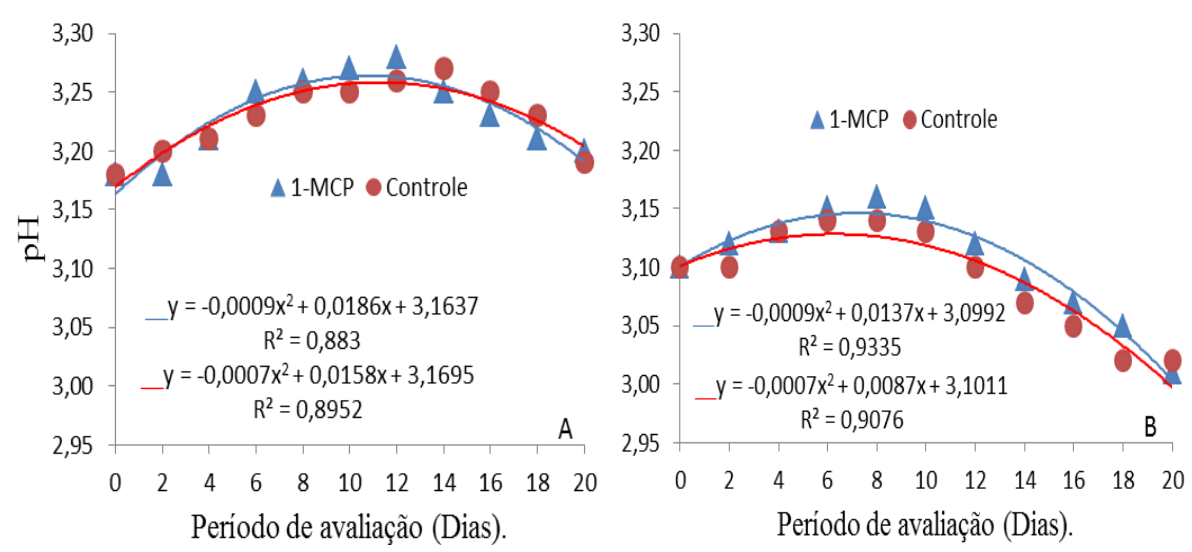

Figura 3. pH de frutos de morangueiro das cultivares Albion (A) e San Andreas (B) com e sem tratamento de 1-MCP e armazenados sob temperatura de $4 \pm 1{ }^{\circ} \mathrm{C}$ e UR de $90 \% \pm 5 \%$ por 20 dias. Vitória da Conquista - BA, 2016.

Ao contrário do que foi observado por Silva (2010) [12] que estudando morangos da cultivar Oso-Grande observou teores de sólidos solúveis mais elevados para os frutos sem 1-MCP durante o armazenamento, neste trabalho não foi observada nenhuma diferença entre os tratamentos.

O teor de sólidos solúveis aumentou até o oitavo dia, com posterior decréscimo para ambas as cultivares (Figura 4). Este comportamento também foi observado por Moraes et al. (2008) [22] que estudando a influência do tempo de armazenamento a $1^{\circ} \mathrm{C}$ na qualidade de morango $(C v$. OsoGrande e Sweet Charlie) verificaram que o teor médio de sólidos solúveis também aumentou até o oitavo dia do armazenamento.
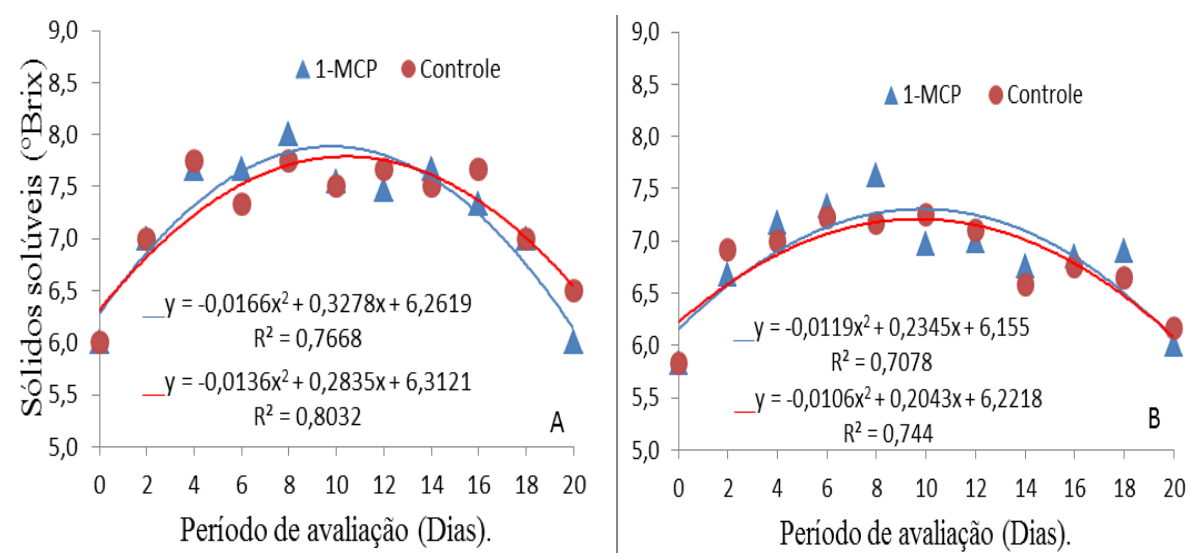

Figura 4. Sólidos solúveis $\left({ }^{\circ}\right.$ Brix) de frutos de morangueiro das cultivares Albion $(A)$ e San Andreas (B) com e sem tratamento de 1-MCP e armazenados sob temperatura de $4 \pm 1^{\circ} \mathrm{C}$ e UR de $90 \%$ $\pm 5 \%$ por vinte dias. Vitória da Conquista - BA, 2016.

O aumento dos sólidos solúveis durante o armazenamento se deve à degradação dos polissacarídeos e a sua transformação em açúcares solúveis. Seu decréscimo após certo período de armazenamento ocorre devido ao uso desses açúcares como fonte energética para o metabolismo.

O valor médio de sólidos solúveis da cultivar Albion foi superior ao da cultivar San Andreas (7,23 ${ }^{\circ}$ Brix e 6,80 $0^{\circ}$ Brix, respectivamente), corroborando com Antunes (2014) [19] que também relatou maior teor de sólidos solúveis na cultivar Albion $\left(6,95^{\circ}\right.$ Brix) em relação à cultivar San Andreas $\left(6,57^{\circ} \mathrm{Brix}\right)$. Os valores de sólidos solúveis observados neste trabalho estão dentro dos teores considerados para o morango que pode variar de 5,4 a 9,8 Brix, sobretudo devido às diferenças genéticas de cada cultivar $[23,24]$ e também das condições de cultivo, colheita e armazenamento. 
A acidez titulável é dada pela presença dos ácidos orgânicos que servem de substratos para a respiração. No morango o principal ácido é o cítrico. Não houve diferença estatística entre os frutos tratados com 1-MCP e os frutos controle de ambas as cultivares. Observou-se diferença significativa entre as cultivares e dias de armazenamento.

É possível que o 1-MCP não tenha exercido efeito sobre a acidez titulável devido ao comportamento não climatérico do morango, associado à baixa temperatura de armazenamento, o que fez com que o metabolismo tenha sido lento e a produção de etileno tão baixa que o efeito do 1-MCP não pode ser observado. Na figura 5 é possível observar comportamento similar para as duas cultivares avaliadas, onde a acidez titulável aumentou até o décimo dia do armazenamento com posterior diminuição.
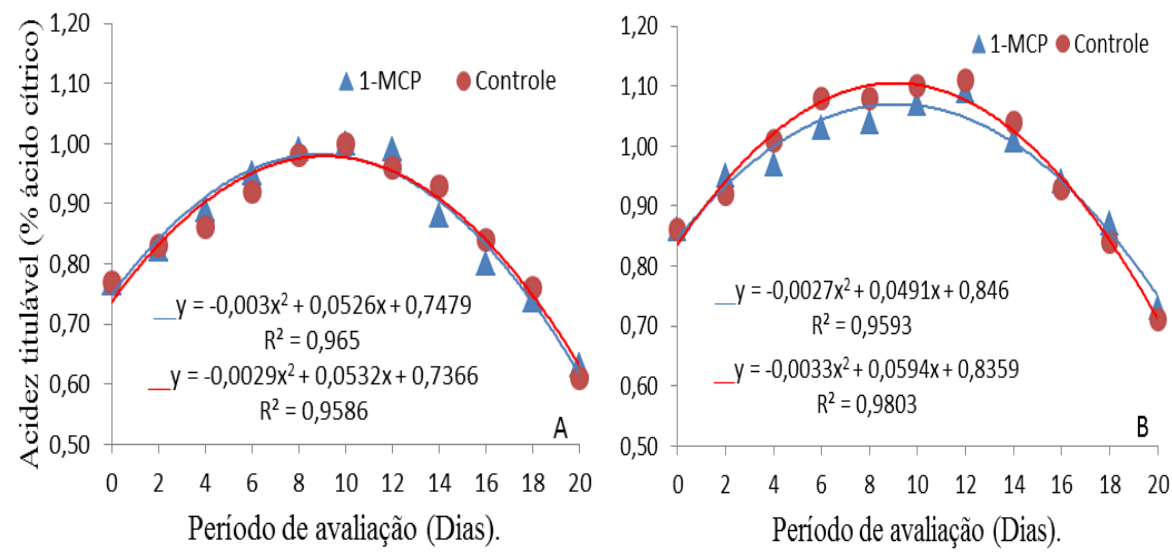

Figura 5. Acidez titulável (\% de ácido cítrico) de frutos de morangueiro das cultivares Albion (A) e San Andreas (B) com e sem tratamento de 1-MCP e armazenados sob temperatura de $4 \pm I^{\circ} \mathrm{C}$ e UR de 90\% $\pm 5 \%$ por 20 dias. Vitória da Conquista - BA, 2016 .

A variação durante o armazenamento foi de $-19,48 \%$ para a cultivar Albion $(0,77 \%$ e $0,62 \%$ de ácido cítrico no dia zero e no dia vinte, respectivamente) e de -16,28\% para a cultivar San Andreas ( $0,86 \%$ e $0,72 \%$ de ácido cítrico no dia zero e no dia vinte, respectivamente), com a cultivar San Andreas se apresentando mais ácida durante todo o período da avaliação.

Os valores encontrados neste trabalho ficaram abaixo dos observados por Antunes et al.(2014) [19], que estudando a qualidade de seis cultivares morango observou variação na acidez titulável de 0,99 a 1,34\% de ácido cítrico para a cultivar Albion e de 1,04 a 1,51 \% de ácido cítrico para a cultivar San Andreas.

Durante o amadurecimento é esperada a redução dos teores de acidez, pois os ácidos orgânicos são utilizados no metabolismo dos frutos, sendo convertidos em açúcares ou servindo de substrato para o processo respiratório. Porém, neste trabalho, durante os primeiros dias de armazenamento houve aumento da acidez titulável, devido, provavelmente, ao comportamento não-climatérico do morango somado ao menor metabolismo dos frutos quando submetidos à baixa temperatura. Comportamento também observado por Campos et al. (2011) [25] que avaliando a aplicação de revestimentos biodegradáveis na conservação pós-colheita de morangos orgânicos (cv. Camarosa), acondicionados em embalagens plásticas e armazenados a $10^{\circ} \mathrm{C}$, também observaram aumento do teor de acidez titulável até o nono dia para o tratamento controle, e similarmente notado por Cardoso et al. (2012) [26] que verificaram que a cultivar Diamante apresentou aumento da acidez titulável no início do armazenamento com posterior redução.

A relação dos sólidos solúveis com a acidez titulável (SS/AT) proporciona uma melhor avaliação do sabor dos frutos, pois possibilita uma melhor avaliação ao relacionar o sabor doce com o ácido. Durante o armazenamento houve aumento da relação SS/AT em ambas as cultivares, independentemente do tratamento aplicado (Figura 6). Observou-se diferença significativa para as cultivares e dias de armazenamento, não havendo variação para os frutos com 1-MCP e frutos controle. O efeito neutro do 1-MCP na relação sólidos solúveis e acidez titulável é resultado do 
comportamento indiferente dos sólidos solúveis e da acidez titulável nos frutos quando tratados com 1-MCP.

A maior relação de SS/AT observada na cultivar Albion se deve ao maior teor de sólidos solúveis e menor acidez titulável dessa cultivar, como discutido anteriormente. Nenhuma das cultivares avaliada atingiu a relação SS/AT ideal, que é de 8,75 [6]. Antunes et al. (2014) [19] estudando a qualidade pós-colheita de várias cultivares de morango, também observaram que nenhuma das cultivares atingiu a relação considerada como ideal. A autora relatou que a cultivar Albion apresentou relação SS/AT 7,29 e a cultivar San Andreas de 6,53, valores próximos ao observado neste trabalho. Com o aumento da relação sólidos solúveis e acidez titulável no amadurecimento, os frutos apresentam-se com um sabor mais agradável devido ao equilíbrio do teor de açúcares e ácidos.
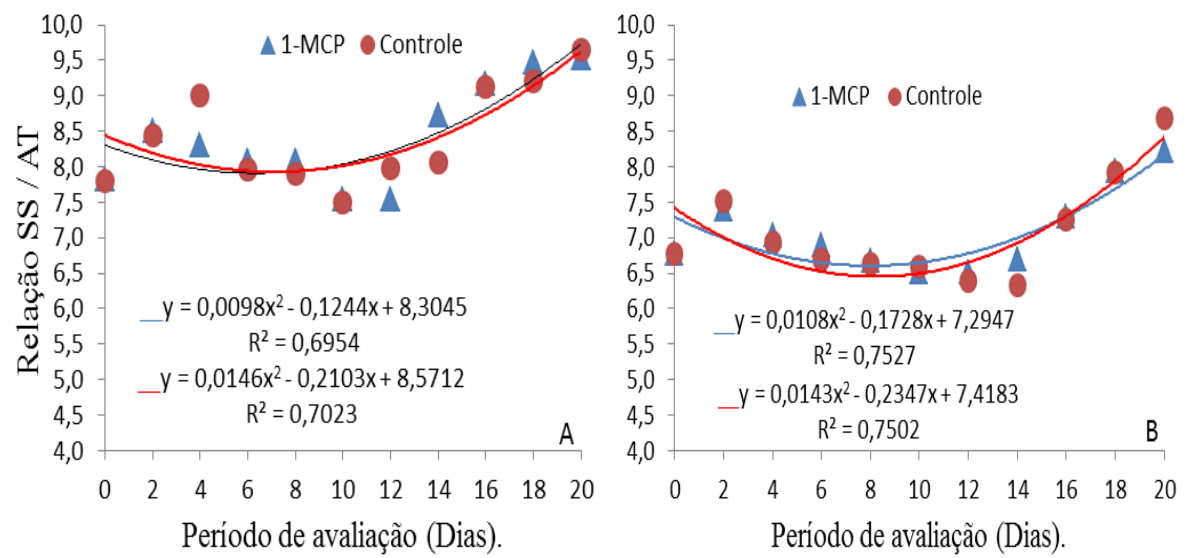

Figura 6. Relação sólidos solúveis e acidez titulável de frutos de morangueiro das cultivares Albion (A) e San Andreas (B) com e sem tratamento de 1-MCP e armazenados sob temperatura de $4 \pm l^{\circ} \mathrm{C}$ e UR de $90 \% \pm 5 \%$ por 20 dias. Vitória da Conquista - BA, 2016.

$\mathrm{O}$ ácido ascórbico é a forma reduzida da vitamina $\mathrm{C}$, sendo mais estável, tem sido amplamente utilizado para quantificar essa vitamina em frutas e hortaliças. Não houve diferença significativa entre os frutos tratados com 1-MCP e os frutos controle, apenas entre os dias do armazenamento e também entre as cultivares. Ocorreu diminuição do teor de ácido ascórbico em ambas as cultivares ao longo de todo o armazenamento (Figura 7).
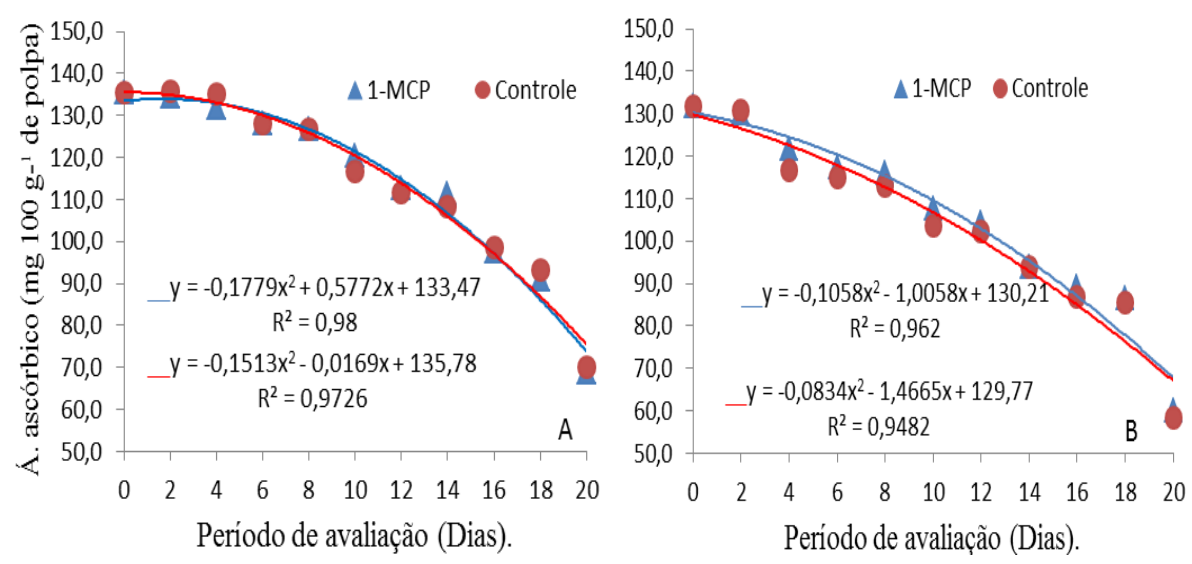

Figura 7. Ácido ascórbico (mg $100 \mathrm{~g}^{-1}$ de polpa) de frutos de morangueiro das cultivares Albion (A) e San Andreas (B) com e sem tratamento de 1-MCP e armazenados à temperatura de $4 \pm 1^{\circ} \mathrm{C}$ e UR de $90 \% \pm 5 \%$ por 20 dias. Vitória da Conquista - BA, 2016. 
A cultivar Albion apresentou teor médio de ácido ascórbico de 114,38 mg 100 g-1 de polpa, enquanto na cultivar San Andreas o teor médio foi de $104,26 \mathrm{mg} 100 \mathrm{~g}-{ }^{1}$ de polpa. Esses valores discordam de Antunes et al. (2014) [19]que reportaram maiores teores de ácido ascórbico para a cultivar San Andreas (74,74 mg 100 g-1 de polpa) quando comparado com a cultivar Albion (49,76 mg $100 \mathrm{~g}^{-1}$ de polpa).

A redução do ácido ascórbico também foi verificada por Vieites et al. (2006) [27] ao avaliarem a conservação de morango ( $c v$. Oso-Grande) armazenado em atmosfera modificada e por Brackmann et al. (2011) [28] em diferentes cultivares de morangueiro durante o armazenamento em temperatura de $0,5^{\circ} \mathrm{C}$. Essa redução é esperada durante o armazenamento, devido à alta atividade da enzima ácido ascórbico oxidase, que oxida de forma irreversível o ácido ascórbico a ácido L-ascórbico (forma principal e biologicamente ativa da vitamina C) e que, por ser extremamente termolábil, é rapidamente hidrolisado ao ácido 2,3-diceto-L-gulônico, por meio de uma abertura irreversível no anel da lactona, perdendo a atividade vitamínica [6].

No morango as antocianinas estão presentes em elevadas concentrações, contribuindo significativamente para a atividade antioxidante do fruto. Foram observadas diferenças significativas apenas para os dias de armazenamento, não havendo nenhuma distinção entre os frutos com 1-MCP e frutos controle, independentemente da cultivar avaliada (Figura 8).
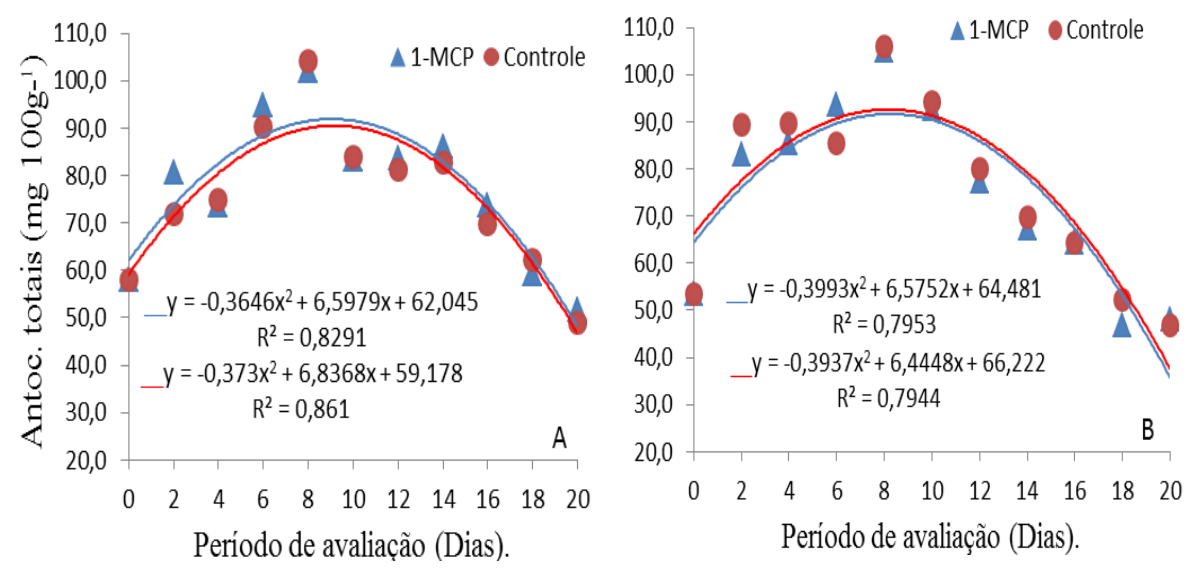

Figura 8. Antocianinas totais (mg $100 \mathrm{~g}_{-1}^{1}$ de polpa) de frutos de morangueiro das cultivares Albion (A) e San Andreas (B) com e sem tratamento de 1-MCP e armazenados sob temperatura de $4 \pm l^{\circ} \mathrm{C}$ e UR de $90 \% \pm 5 \%$ por 20 dias. Vitória da Conquista -BA, 2016.

Moraes e outros (2008) [22] determinando as características físicas e químicas de morango processado minimamente e conservado sob refrigeração e atmosfera controlada, também verificaram que os teores de antocianinas aumentaram durante o armazenamento por sete dias.

Os resultados encontrados neste estudo (média de 64,3 a 45,04 mg 100g-1 no dia 0 e no dia 20 , respectivamente) estão próximos daqueles observados por Bordignon Júnior et al. (2009) [29] que, avaliando o teor de antocianinas em frutos de morango, encontraram teores de 76,60 mg $100 \mathrm{~g}-1$ de morango. E ficaram acima dos resultados encontrados por Buendia et al. (2010) [30] que analisando-a composição química de compostos fenólicos em 15 cultivares de morango, constataram teores médios de antocianinas entre 20,2 e 47,4 mg $100 \mathrm{~g}-{ }^{1}$.

O 1-MCP não foi eficiente em alterar os teores de carotenoides em ambas as cultivares avaliadas. Ao longo do período ocorreu aumento nos teores de carotenoides totais para as cultivares, porém, na Albion o aumento foi menor que San Andreas, sendo que a primeira apresentou um crescimento de $82,9 \%$ (2,98 no dia 0 e $\left.5,45 \mathrm{mg} 100 \mathrm{~g}^{1}\right)$ e a segunda um aumento de $150,2 \%$ no teor de carotenoides (2,73 no dia 0 e 6,83 mg 100g') (Figura 9). Isso demonstra que a cultivar San Andreas apresentou maiores teores de carotenoides que a cultivar Albion e, possivelmente, maior potencial para sintetizá-los durante o armazenamento. 

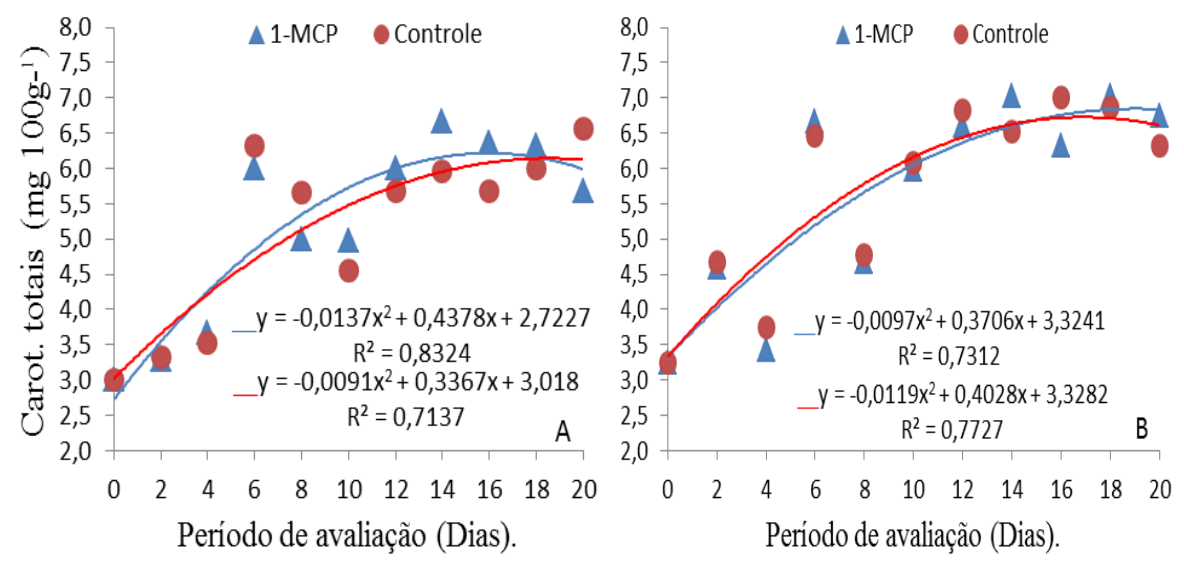

Figura 9. Carotenoides totais ( $m g 100 \mathrm{~g}^{-1}$ de polpa) de frutos de morangueiro das cultivares Albion (A) e San Andreas (B) com e sem tratamento de 1-MCP e armazenados sob temperatura de $4 \pm l^{\circ} \mathrm{C}$ e UR de $90 \% \pm 5 \%$ por 20 dias. Vitória da Conquista - BA, 2016.

Por se tratar de pigmentos, durante o amadurecimento dos frutos os carotenoides podem já estar presentes, tornando-se visíveis com a degradação da clorofila, também podem ser sintetizados simultaneamente com a sua degradação. Portanto, os frutos já podem ser colhidos com altos teores de carotenoides e ainda elevarem ou manterem esses teores ao longo do armazenamento, comportamento observado neste trabalho.

\section{CONCLUSÃO}

O uso do 1-MCP, não é eficiente em alterar as características de qualidade avaliadas, pois estas evoluem normalmente em ambas as cultivares;

A cultivar Albion apresenta os melhores teores de pH, ácido ascórbico, sólidos solúveis, relação sólidos solúveis e acidez titulável e carotenoides totais que a cultivar San Andreas.

$\mathrm{O}$ armazenamento refrigerado, $4 \pm 1{ }^{\circ} \mathrm{C}$ e UR de $90 \% \pm 5 \%$, preserva a qualidade dos morangos até os vinte dias após a colheita, porém os melhores teores das características avaliadas são observados até $\mathrm{o} 10^{\circ}$ dia de armazenamento.

\section{AGRADECIMENTOS}

À Coordenação de Aperfeiçoamento de Pessoal de Nível Superior pela concessão da bolsa de estudo durante o curso de mestrado e ao Programa de Pós-Graduação em Agronomia, área de Concentração em Fitotecnia, da Universidade Estadual do Sudoeste da Bahia - UESB.

\section{REFERÊNCIAS BIBLIOGRÁFICAS}

1. FAO-Organização das Nações Unidas para Agricultura e Alimentação. 2015. Agricultural Production / strawberry. Disponível em: 〈http://faostat.fao.org〉. Acesso em: mar. 2017.

2. Carvalho SF. Produção, qualidade e conservação pós-colheita de frutas de diferentes cultivares de morangueiro nas condições edafoclimáticas de Pelotas-RS (dissertação). Pelotas (RS): Universidade Federal de Pelotas; 2013. 104p.

3. Rosa HT, Streck NA, Walter LC, Andriolo JL, Silva MR. Crescimento vegetativo e produtivo de duas cultivares de morango sob épocas de plantio em ambiente subtropical. Revista Ciência Agronômica. 2013 Jul;44(3):604-613.

4. Dias CN, Marinho AB, Arruda RS, Silva MJP, Pereira ED, Fernandes CNV. Produtividade e qualidade do morangueiro sob dois ambientes e doses de biofertilizante. Revista Brasileira de Engenharia Agrícola e Ambiental. 2015;19(10):961-966.

5. Caner C, Aday MS, Demir M. Extending the quality of fresh strawberries by equilibrium modified atmosphere packaging. European Food Research and Technology. 2008;227:1575-1583. 
6. Chitarra MIF, Chitarra AB. Pós-colheita de frutos e hortaliças: fisiologia e manuseio. 2ed. Lavras: UFLA; 2005. $783 \mathrm{p}$.

7. Morais PLD, Lima LCO, Alves RE, Donizeti J, Alves AP. Conservação pós-colheita de sapoti submetido a diferentes doses de 1-metilciclopropeno. Revista Ceres. 2007 Nov;316(54):517-525.

8. Pinheiro ACM, Vilas Boas EVB, Bolini HM. A. Prolongamento da vida pós-colheita de bananas-maçã submetidas ao 1-metilciclopropeno (1-MCP) - qualidade sensorial e física. Ciência de Tecnologia e Alimentos. $2010 \mathrm{Jan} ; 30(1): 132-137$.

9. Fante CA, Vilas Boas AC, Costa AC, Silva EP, Oliveira MC, Lima LCO. 1-MCP nos aspectos fisiológicos e na qualidade pós-colheita de maçãs Eva durante o armazenamento refrigerado. Ciência Rural. 2013 Dez;43(12):2142-2147.

10. Mazzurana ER, Argenta LC, Amarantec VT, Steffens CA. Potenciais benefícios do aumento da temperatura de armazenagem em atmosfera controlada de maçãs 'gala' tratadas com 1-MCP. Revista Brasileira de Fruticultura. 2016 Fev;38(1):43-52.

11. Cábia NC, Vieites RL. Alterações físicas do abacate 'hass' submetido a aplicação de 1-mcp. Energia na Agricultura. 2013 Abr;28(2):129-134.

12. Silva PA. Manutenção da qualidade de morangos submetidos ao 1-MCP e armazenados em temperatura ambiente e refrigerada (tese). Lavras (MG): Universidade Federal de Lavras; 2010. 137p

13. Tian MS, Prakash S, Elgar HJ, Young H, Burmeister DM, Ross GS. Responses of strawberry fruit to 1Methylcyclopropene (1-MCP) and ethylene. Plant Growth Regul. 2000;32:83-90.

14. Ku VVV, Wills RBH, Yehoshua BS. 1-Methyl cyclopropene can differentially affect the postharvest life of strawberries exposed to ethylene. Horticultural Science. 1999;34:119-120.

15. Association of official analytical chemistry. Official methods of analysis of the association of official agriculture chemistry. 18. ed. Mayland: AOAC; 2005. 1094 p.

16. Instituto Adolfo Lutz. Métodos químicos-físicos para análises de alimentos. São Paulo. $4^{\circ}$. ed. São Paulo Instituto Adolfo Lutz; 2008.

17. Sims DA, Gamon JA. Relationship between pigment content and spectral reflectance across a wide range of species, leaf structures and developmental stages. Remote Sensing of Environment. 2002; 81: 337-354.

18. Ferreira, DF. Sisvar: a Guide for its Bootstrap procedures in multiple comparisons. Ciência agrotecnologia 2014;38(2):109-112.

19. Antunes MC, Cuquel FL, Zawadneak MAC, Mogor AF, Resende JTV. Post-harvest quality of strawberry produced during two consecutive seasons. Horticultura Brasileira. 2014 Abr;32(2):168-173.

20. García JM, Medina RJ, Olías JM. Quality of strawberries automatically packed in different plastic films. Journal of Food Science. 2005;63(6):1037-1041.

21. Kader AA. Postharvest biology and technology: na overview. In: Kaber AA, editor. Postharvest technology of horticultural crops. 2002. 3. ed. Davis: University of California, 4;39-47.

22. Moraes IVM. et al. Características físicas e químicas de morango processado minimamente e conservado sob refrigeração e atmosfera controlada. Ciência e Tecnologia de Alimentos. 2008 Abr;28(2).

23. Cecatto AP, Calvete EO, Nienow AA, Costa RC, Mendonça HFC, Pazzinato AC. Culture systems in the production and quality of strawberry cultivars. Acta Scientiarum. 2013;35(4):471-478.

24. Lemiska A, Pauletti V, Cuquel FL, Cassilha Zawadneak MA. Produção e qualidade da fruta do morangueiro sob influência da aplicação de boro. Ciência Rural. 2014;44(4):622-628.

25. Campos RP, Kwiatkowski A, Clemente E. Post-harvest conservation of organic strawberries coated with cassava starch and chitosan. Revista Ceres. 2011 Set;58(5):554-560.

26. Cardoso LM, Deus VA, Silva EB, Andrade Júnior VC, Dessimoni-Pinto NAV. Qualidade pós-colheita de morangos cv. 'diamante' tratados com cloreto de cálcio associado a hipoclorito de sódio. Alimento e Nutrição. 2012 Out;23(4):583-588.

27. Vieites RL, Evangelista RM, Silva CS, Martins ML. Conservação do morango armazenado em atmosfera modificada. Semina: Ciências Agrárias, Londrina. 2006 Abr;27(2):243-252.

28. Brackmann A, Pavanello EP, Both V, Janisch DI, Schmitt OJ, Giménez G. Avaliação de genótipos de morangueiro quanto à qualidade e potencial de armazenamento. Revista Ceres. 2011 Set;58(5):524-547.

29. Bordignon Júnior CL. Análise química de cultivares de morango em diferentes sistemas de cultivo e épocas de colheita [dissertação]. Passo Fundo (RS): Universidade de Passo Fundo; 2008, 132p.

30. Buendia B, Gil MI, Tudela JÁ, Gady AL, Medina JJ, Soria C, Lopez JM, Tomas-Barberan FA. HPLCMS analysis of proanthocyanidin oligomers and other phenolics in 15 strawberry cultivars. Journal of Agricultural and Food Chemistry. 2010 Apr;58(7):3916-26. 